\title{
PREVENCIJA NASILJA NA STADIONIMA I KOMFOR GLEDALACA SA ASPEKTA SAGLEDIVOSTI SPORTSKOG DOGAĐAJA
}

\author{
Bratislav Petrović ${ }^{1}$ \\ UDK=343.85:351.758 \\ https://doi.org/10.18485/fb_ubur.2018.1.ch19 \\ ${ }^{1}$ Ministarstvo omladine i sporta Republike Srbije, Beograd \\ b.petrovic.sportskiobjekti@gmail.com
}

\section{Sažetak}

Nasilje i nedolično ponašanje na velikim sportskim događajima postalo je globalan fenomen i ugrožava osnovne vrednosti sporta. Stadioni su najznačajniji sportski objekti, zato što se u njima održavaju velika međunarodna ili nacionalna sportska takmičenja sa najvećim brojem gledalaca. Mnoga istraživanja ukazuju na to da je nasilje najčešće na fudbalskim utakmicama. Mesto rizika na stadionu jeste gledalište. S pojavom nasilja i nedoličnog ponašanja na stadionima ukazala se potreba za obezbeđenjem mera za sprečavanje ove negativne društvene pojave. U radu se ukazuje na mere i uslove koje treba da ispuni sportski objekat u cilju sprečavanja nasilja i nedoličnog ponašanja na velikim sportskim takmičenjima. Među najznačajnijim merama su organizovanje sigurnosne zone, odnosno minimalne udaljenosti gledališta od borilišta, razdvajanje gledališta na celine i razdvajanje gledališta od borilišta. Pri projektovanju gledališta stadiona potrebno je ostvariti dva osnovna uslova, odnosno gledaocima obezbediti dobru vidljivost borilišta i u isto vreme preduprediti nasilje i nedolično ponašanje gledalaca na tribinama, i time zaštititi gledaoce, sportiste i druge aktere sportskog takmičenja. U radu je analiziran uticaj primene mera prevencije nasilja i nedoličnog ponašanja gledalaca na komfor gledalaca sa aspekta sagledivosti sportskog događaja sa tribina stadiona.

Predmet istraživanja je nacionalna regulativa o sprečavanju nasilja i nedoličnog ponašanja na sportskim priredbama i regulativa u oblasti urbanističkog planiranja i arhitektonskog projektovanja sportske infrastrukture, posebno stadionâ. Proučavani su uslovi za projektovanje gledališta stadionâ, posebno sa aspekta sagledivosti sportskog takmičenja, odnosno borilišta, udaljenosti gledališta od borilišta i odvajanje gledališta od borilišta. Istovremeno je proučavana regulativa kojom se uređuje sport, a posebno regulativa u vezi sa sprečavanjem nasilja i nedoličnog ponašanja gledalaca na tribinama sportskog objekta za vreme sportskih takmičenja.

Cilj rada je utvrditi korelaciju između projektantskih uslova za obezbeđenje dobre vidljivosti gledaocima sa tribina stadiona i pragmatičnih mera razdvajanja gledališa od borilišta, koje se preventivno primenjuju radi sprečavanja nasilja i nedoličnog ponašanja za vreme velikih sportskih takmičenja.

Ključne reči: sportski objekat, prevencija nasilja, vidljivost 


\section{Uvod}

I bez dubljeg istraživanja istorije sporta, neosporna je činjenica to da je nasilje navijača na sportskim događajima bilo ispoljavano i u dalekoj prošlosti. U savremenom svetu sportska utakmica ili takmičenje pretvara se u borbu za bolji rezultat, a time i prestiž. Stadioni postaju mesta na kojima se ispoljava agresija, a nasilje i nedolično ponašanje postaju globalni fenomeni i ugrožavaju osnovne vrednosti sporta. S pojavom nasilja i nedoličnog ponašanja na sportskim objektima, posebno na stadionima, ukazala se potreba da se obezbede mere za sprečavanje ove negativne društvene pojave.

\section{Sportski objekti}

U užem kontekstu, u fokusu ovog rada su sportski objekati i zato je neophodno, na osnovu regulative u oblasti sporta i sprečavanja nasilja na sportskim priredbama, razjasniti osnovne termine: sportski objekat, sportski teren, gledalište, sportska priredba i prepreke u gledalištu sportskog objekta. Regulativom kojom se uređuje oblast sporta definisan je termin sportski objekti - to su uređene i opremljene površine i objekti namenjeni obavljanju sportskih aktivnosti. Sportski objekat, pored prostora namenjenog sportskim aktivnostima, ima i prateće prostore, gde spada i gledališni prostor. [Zakon o sportu, 2016.]

Sa aspekta sprečavanja nasilja i nedoličnog ponašanja sportski objekti su uže definisani kao objekti namenjeni za održavanje sportskih priredbi, koji pored sportskog terena imaju prostor za gledalište i koji mogu imati i prateći prostor (sanitarni, garderobni, spremišni i druge segmente). [Zakon o sprečavanju nasilja i nedoličnog ponašanja na sportskim priredbama, 2013.]

Sportski teren je određen deo sportskog objekta i definisan je kao prostor na kojem se obavlja sportska aktivnost (sportska igra, takmičenje), gde se uključuje i zaštitna zona sportskog terena, odnosno prostor do gledališta. [Zakon o sprečavanju nasilja i nedoličnog ponašanja na sportskim priredbama, 2013.] Pored prethodno navedene definicije da je gledalište prateći prostor sportskog objekta, gledalište je određeno kao uređen prostor na sportskim objektu koji je namenjen za smeštaj gledalaca (tribine), odnosno prostor uz sportski teren namenjen za gledaoce ako objekat nema tribine. [Zakon o sprečavanju nasilja i nedoličnog ponašanja na sportskim priredbama, 2013.]

Terminološki, u sportskoj regulativi, definisano je da sportska priredba jeste određeni planski pripremljen i sproveden, vremenski ograničen sportski događaj, za koji postoji javni interes i na kojem učestvuje više sportista. [Zakon o sportu, 2016.] Regulativom o sprečavanju nasilja i nedoličnog ponašanja određeno je da sportske priredbe obuhvataju sportska takmičenja i sportske manifestacije. [Zakon o sprečavanju nasilja i nedoličnog ponašanja na sportskim priredbama, 2013.]

U stručnoj sportskoj literturi, u smislu bezbednosti na sportskim igralištima, prepreke ili barijere na sportskom objektu definisane su kao bilo koji elementi 
sportskog objekta, trajnog ili privremenog karaktera, sa ciljem sprečavanja pada ljudi i zadržavanja, zaustavljanja ili usmeravanja ljudi, prvenstveno gledaoca na sportskom događaju u okviru prostora sportskog objekta, kao i neposredno ispred samog objekta za ulaz gledalaca. [Guide to Safety at Sports Grounds, 2008.]

\section{Komfor sagledivosti sportske priredbe}

Jedan od složenih zadataka arhitekture jeste da planira, projektuje, gradi i oprema prostore koji su udobni korisniku. Komfor sportskog objekta arhitekta projektant obezbeđuje pomoću arhitektonskih elemenata prostora. Komfor sagledivosti predstavlja spoj potreba korisnika, odnosno gledalaca, i njihove želje za preglednošću sportskog terena i sportske aktivnosti, odnosno sportskog događaja. Gledaoci na tribinama sportskog objekta treba da imaju jasan i neograničen pogled na celo igralište ili polje sportske aktivnosti. Dizajn gledališnog prostora, a i samog sportskog objekta, treba da obezbedi da se gledaoci ne pomeraju ili ne naprežu kako bi jasno gledali sportski događaj.

U ovom istraživanju sagledivost sportskog događaja definiše se kao optimalno ugodno stanje gledaoca sa aspekta preglednosti sportske aktivnosti sa tribine sportskog objekta. Komfor sagledivosti na stadionu obezbeđuje se primenom adekvatnih standarda sagledivosti.

Dva uslova komfora sportskog objekta, sa aspekta vidnih uslova sagledivosti sportskog terena, odnosno sportske priredbe, jesu:

- razdaljina gledanja, odnosno udaljenost sportskog terena - igrališta ili borilišta od gledalaca na tribini sportskog objekta, i

- sagledivost sportskog terena, odnosno nepostojanje fizičkih ili bilo kakvih prepreka između gledaoca i terena, koje bi umanjile preglednost celog terena - sagledivost sportskog događaja.

U cilju ispunjenja uslova komfora, u pogledu sagledivosti sportskog događaja, propisani su standardi i normativi koji se primenjuju pri projektovanju gledališta sportskog objekta namenjenog sportskim takmičenjima. Tri osnovna proračuna, odnosno uslova pri projektovanju sagledivosti gledališta, jesu:

- optimalna razdaljina gledanja,

- optimalna vidna linija od oka gledaoca do terena $\mathrm{i}$

- uklanjanje ili umanjenje uticaja prepreka i/ili drugih fizičkih ograničenja u fokusu gledanja. [Guide to Safety at Sports Grounds, 2008.]

\subsection{Preporuke za optimalnu razdaljinu glednja kod sportskih objekata/stadiona}

Preporuke za optimalnu razdaljina gledanja, pri arhitektonskom projektovanju stadiona formulisao je Nojfert (Slika 1). 


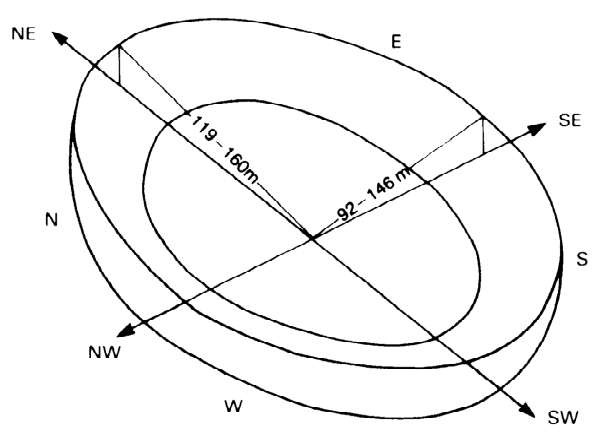

Slika. 1. Optimalne razdaljine gledanja. Izvor: Neufert. E., Architects' Data. Preuzeto 16. maja 2017. sa: https://www.neufert.3th.pdf (isto: Nojfert, E., 1988, Slika 1, str. 414)

Najbolji uslovi vidljivosti su na podužnim stranama, u granicama jednog kružnog segmenta kod stadiona oblika kao na Slici 1. Zbog toga su u Americi prvi stadioni građeni u obliku kao na Slici 1.

$\mathrm{Na}$ osnovu vodiča za projektovanje stadiona Međunarodne federacije fudbalskih asocijacija (FIFA), teoretski, idealna forma za fudbalski stadion jeste kada je prostor za igru što bliže gledaocu, jer gledaocima pruža kvalitetan pogled sa svakog sedišta u gledalištu. [Football Stadiums / Technical recommendations and requirements, 2007.]

Unija evropskih fudalskih asocijacija (UEFA) donela je preporuke za dimenzionisanje gledališta pri projektovanju stadiona, koje se odnose na razdaljinu gledanja, a to su:

- maksimalna razdaljina gledanja iznosi $190 \mathrm{~m}$,

- optimalna razdaljina gledanja iznosi $150 \mathrm{~m} \mathrm{i}$

- pretpostavljena optimalna razdaljina gledanja iznosi $90 \mathrm{~m}$.

[UEFA Guide to Quality Stadiums, 2011.]

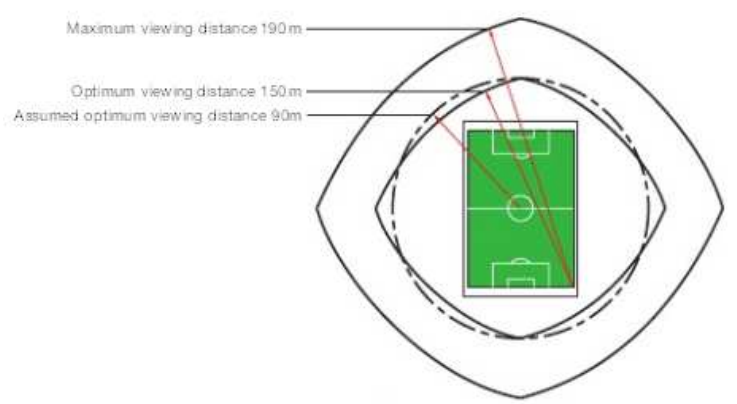

Slika 2. Optimalne razdaljine gledanja. Izvor: UEFA Guide to Quality Stadiums, 2011. Preuzeto 16. maja 2017, sa: https://www.uefa.org/MultimediaFiles/Download/EuroExperience/competitions/General/01/74/38/69/1743869_DOWNLOAD.pdf 


\subsection{Proračun vidne linije}

Raspoređivanje mesta za gledaoce podrazumeva obezbeđenje vidnih uslova za gledanje sportskog događaja. Nadvišenje mesta za sedenje gledalaca na tribinama proračunava se i predstavlja vrednost koja zavisi od horizontalnog rastojanja fokusne tačke na sportskom terenu i vertikalne visine oka gledaoca i tačke na terenu.

Proračunom vidne linije obezbeđuje se da gledalac na tribini vidi definisanu fokusnu tačku na terenu preko vrha glave posmatrača koji se nalazi neposredno, kao i dalje, ispred njega. Bolji kvalitet vidne linije obezbeđuje da gledalac ostane u sedištu gledališta, odnosno na svome mestu, što omogućava siguran smeštaj i bezbednost gledalaca.

Preporučena vrednost „C“ za gledaoce varira u zavisnosti od sporta, kao i izbora fokusne tačke. Uz napomenu da se fokusna tačka pomera u zavisnosti od razvoja sportske aktivnosti i zavisi od položaja gledaoca, odnosno da li sportski događaj posmatra gledalac koji sedi na sedištu, sedi u invalidskim kolicima ili stoji.

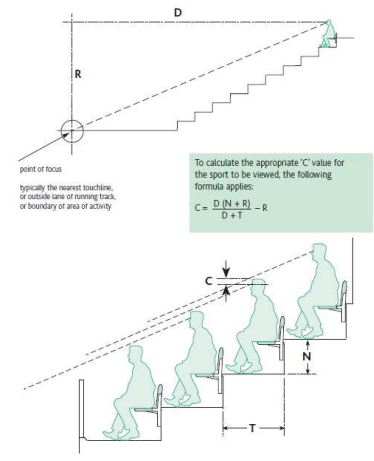

Slika. 3. Grafički prikaz proračuna vidne linije - nadvišenja sedišta gledališta. Izvor: Department for Culture, Media and Sport, 2008, Dijagram 12.1, str. 109. Preuzeto 15. maja 2017. sa: http://www.safetyatsportsgrounds.org.uk/sites/default/files/publications/green-guide.pdf

Kvalitet vidne linije se izražava kao vrednost C. Na osnovu propisa standardna formula za proračun kvaliteta vidne linije, odnosno nadvišenja sedišta jeste:

$$
C=\frac{D(N+R)}{D+T}-R
$$

gde je:

$\mathrm{C}=$ vrednost nadvišenja,

$\mathrm{D}=$ horizontalno rastojanje od oka lica svakog individualnog položaja posmatrača do tačke fokusa (ivice terena),

$\mathrm{N}$ = podignuta visina svakog pojedinačnog reda sedišta,

$\mathrm{R}$ = vertikalna visina između nivoa očiju lica svakog individualnog posmatrača $i$ tačke fokusa (ivice terena) $\mathrm{i}$ $\mathrm{T}=$ dužina do svakog pojedinačnog reda sedišta.

[UEFA Guide to Quality Stadiums, 2011.] 
Ako gledaoci stoje na tribini gledališta sportskog objekta, može se zaključiti, izuzev onih koji se nalaze u prvom redu, da imaju lošiju vidnu liniju. Smanjenje vidljivog dela oblasti sportske aktivnosti, odnosno sagledivosti sportske aktivnosti, uključuje i pomeranja, naprezanja, istezanja, guranja i slične aktivnosti koje su izraženije kod gledalaca koji stoje.

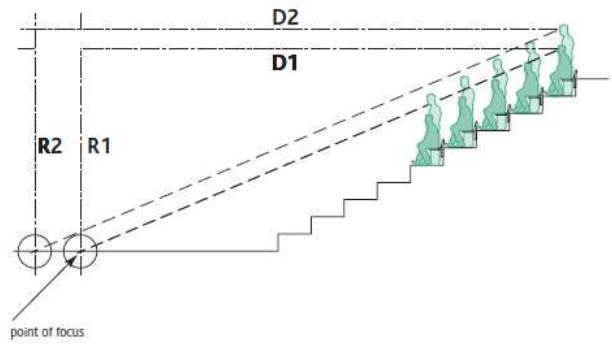

Slika 4. Grafički prikaz komparacije vidnih linija - gledalaca koji sede i gledalaca koji stoje. Izvor: Department for Culture, Media and Sport, 2008. Dijagram 12.2, str. 110. Preuzeto 15. maja 2017. sa:

http://www.safetyatsportsgrounds.org.uk/sites/default/files/publications/green-guide.pdf

Legenda dijagrama na Slici 4:

D1 - horizontalno rastojanje od tačke fokusa na terenu do oka gledaoca koji sedi na tribini sportskog objekta,

R1 - vertikalna visina od tačke fokusa do oka gledaoca koji sedi na tribini sportskog objekta

D2 - horizontalno rastojanje od tačke fokusa na terenu do oka gledaoca koji stoji na tribini sportskog objekta,

R2 - vertikalna visina od tačke fokusa do oka gledaoca koji stoji na tribini sportskog objekta.

Jednako važno je da se prilikom obezeđivanja vidljivosti gledaoca sa tribina razmišlja i o drugim posmatračima, a posebno o osobama koji su korisnici invalidskih kolica.

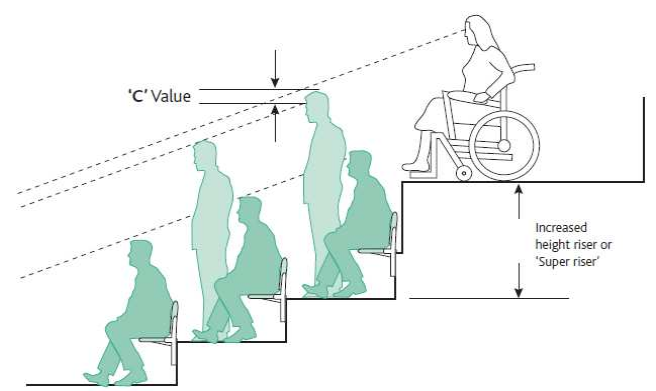

Slika 5. Grafički prikaz vidne linije gledaoca koji sedi u invalidskim kolicima.

Izvor: Department for Culture, Media and Sport, 2008,

Diagram 12.3, str. 111. Preuzeto 15. maja 2017. godine sa:

http://www.safetyatsportsgrounds.org.uk/sites/default/files/publications/green-guide.pdf 
Prilikom projektovanja gledališta potrebno je ostvariti optimizaciju sagledivosti, odnosno ostvariti liniju vidljivosti sa svih sedišta gledališta, i obezbediti preglednost terena optimalnom razdaljinom između gledalaca i najbliže i najudaljenije tačke na terenu, odnosno celog terena. Proračun vidnih linija za različite sportove uvršćen je u Evropske standarde pod oznakom: BS EN 13200:2003 Spectator facilities.

\subsection{Ograničenja/prepreke u fokusu gledanja}

Neki od arhitektonskih elementa sportskog objekta koji mogu predstavljati ograničenja, odnosno prepreke u fokusu gledanja sportskog događaja sa tribine jesu:

- elementi konstrukcije tribina, krovne konstrukcije ili slični zakloni,

- bočni zidovi, ekrani i slični zastori,

- barijere, ograde i rampe za odvajanje, usmeravanje kretanja gledalaca i slični objekti,

- platforme i konstrukcije za reflektore, kamere i slična pomagala,

- pomoćni uređaji, zaštitne mreže i drugo.

[Guide to Safety at Sports Grounds, 2008.]

Projektantima sportskih objekata koji su namenjeni sportskim takmičenjima preporučuje se da u prostoru između terena i gledališta, kao i u okviru samog prostora gledališta, eliminišu ili svedu na najmanju moguću meru fizičke ili bilo kakve prepreke koje bi umanjile preglednost terena, odnosno sagledivost sportskog događaja.

\section{Nasilje i nedolično ponašanje na sportskim priredama}

Na osnovu analitičkih i statističkih podataka Ministarstva unutrašnjih poslova Republike Srbije, najčešći oblici nasilja i nedoličnog ponašanja na sportskim priredbama u Srbiji, koji su u vezi sa sportskim objektom, posebno sa prostorom gledališta, sportskim terenom, sportskim takmičenjem i akterima sportskog događaja, jesu: - fizički napad na učesnike sportske priredbe, odnosno fizički obračun između učesnika na sportskoj priredbi,

- bacanje predmeta (pirotehničkih sredstava, motki, flaša i sličnih stvari) na sportski teren ili u gledalište,

- oštećivanje sportskog objekta, opreme, uređaja i instalacija na sportskom objektu na kojem se održava sportska priredba,

- izazivanje nereda ili uništavanje imovine prilikom dolaska, odnosno odlaska sa sportske priredbe ili u sportskom objektu, remećenje toka sportske priredbe, ugrožavanje bezbednosti učesnika sportske priredbe ili trećih lica,

- neovlašćeni ulazak na sportski teren, odnosno u službene prostorije i službene prolaze sportskog objekta ili u deo gledališta sportskog objekta koji je namenjen protivničkim navijačima,

- korišćenje pirotehničkih sredstava i drugih predmeta i sredstava kojima može da se ugrozi bezbednost učesnika u sportskoj priredbi ili ometa tok sportske priredbe, 
- paljenje navijačkih rekvizita, opreme sportskog objekta ili drugih predmeta na sportskom objektu.

[Nacionalna strategija za borbu protiv nasilja i nedoličnog ponašanja na sportskim priredbama za period od 2013. do 2018. godine, 2013.]

\subsection{Mere za sprečavanje nasilja i nedoličnog ponašanja na sportskim priredbama pojačanog rizika}

Nadležni granski sportski savez Republike Srbije, odnosno organizator sportske priredbe, proglašava sportsku priredbu povećanog rizika na osnovu akta nadležnog sportskog saveza ili na preporuku Ministarstva unutrašnjih poslova, kad posebne okolnosti ukazuju da na sportskoj priredbi može doći do nasilja ili nedoličnog ponašanja gledalaca. U cilju sprečavanja nasilja i nedolilčnog ponašanja doneta je regulativa kojom su propisane odgovarajuće mere kakve treba, između ostalog, da primeni organizator sportske priredbe na sportskom objektu koji je namenjen održavanju velikih sportskih takmičenja pojačanog rizika. [Zakon o sprečavanju nasilja i nedoličnog ponašanja na sportskim priredbama, 2013.]

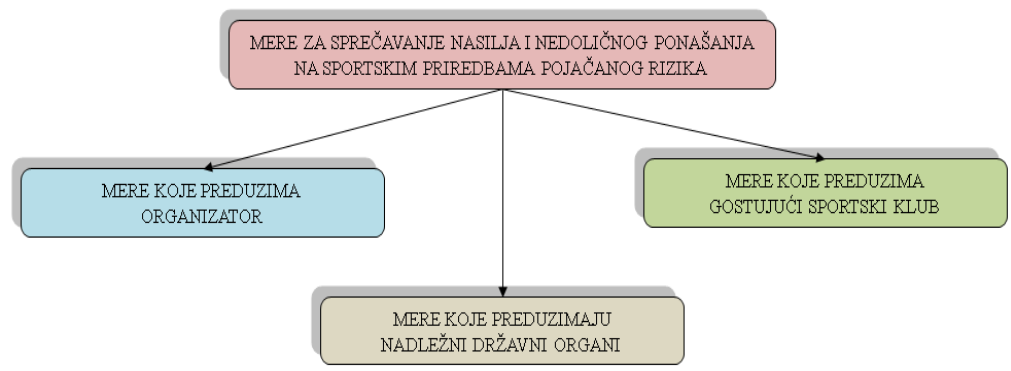

Slika 6. Grafički prikaz vrste mera za sprečavanje nasilja i nedoličnog ponašanja na sportskim priredbama pojačanog rizika. Izvor: Bošković i Petrović, 2014, str. 206.

U ovom istraživanju analizirane su relevantne mere kakve preduzima organizator sportske priredbe pojačanog rizika koje se odnose na arhitektonske elemente sportskog objekta (prvenstveno stadiona).

\subsection{Specifičnosti sportskih objekata u vezi s merama za sprečavanje nasilja}

Uspešnost ostvarivanja bezbednosti i sigurnosti na stadionu predstavlja rezultat primene standardâ i normativâ izgradnje sportskog objekta, još u fazi projektovanja od strane arhitekte, i mera za prevenciju nasilja i nedoličnog ponašanja na sportskim priredama, koje blagovremeno preduzima na sportskom objektu menadžer tog objekta i organizator sportske priredbe. Uslovi koje treba da ispuni sportski objekat, u cilju ispunjenja mera za sprečavanje nasilja i nedoličnog ponašanja na sportskim priredbama pojačanog rizika, predstavljaju specifičnosti sportskog objekta. 
$\mathrm{Na}$ osnovu zakona, organizator sportske priredbe povišenog rizika dužan je, između ostalog, da obezbedi održavanje sportske priredbe u sportskom objektu koji ima: - odgovarajuće ograde za sprečavanje ulaska gledalaca sa tribina na sportski teren i - odgovarajuće ograde za razdvajanje protivničkih grupa navijača na tribinama sportskog objekta - stadiona.

[Zakon o sprečavanju nasilja i nedoličnog ponašanja na sportskim priredbama, 2013.]

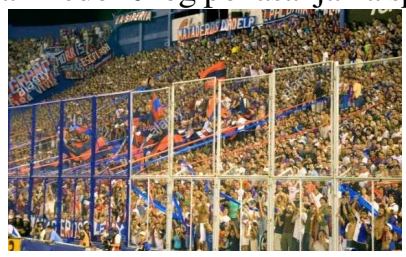

Slika. 7. Ograda između sportskog terena i gledališta. Izvor: Crowds behind security fences watch a soccer game at the West Stadium in Buenos Aires, Argentina.

Preuzeto 15. maja, 2017. sa: http://www.alamy.com/stock-photo-crowds-behind-security-fences-watch-a-soccer-game-at-the-west-stadium-6522952.html

Od strane Međunarodne federacije fudbalskih asocijacija (FIFA) analizirana su tri načina odvajanja sportskog terena od gledališta sportskog objekta (posebno stadiona) i prikazani su grafičkim crtežima na Slici 8.
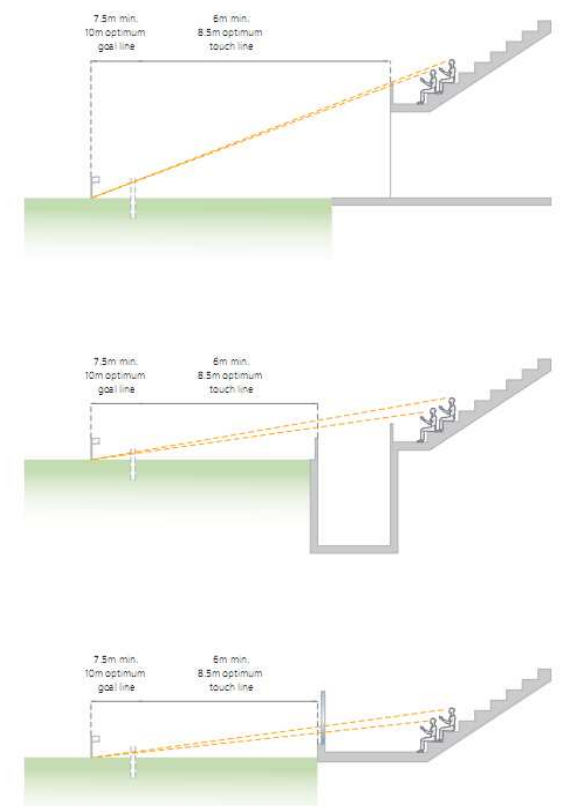

Slika. 8. Načini odvajanja sportskog terena od gledališta:

a) podignuta sedišta tribine, b) šanac, c) ograda.

Izvor: Football Stadiums / Technical recommendations and requirements, 2007.

Preuzeto 15. maja 2017. sa: http://www.ksi.is/media/mannvirki/FIFA_Football_Stadiums.pdf 


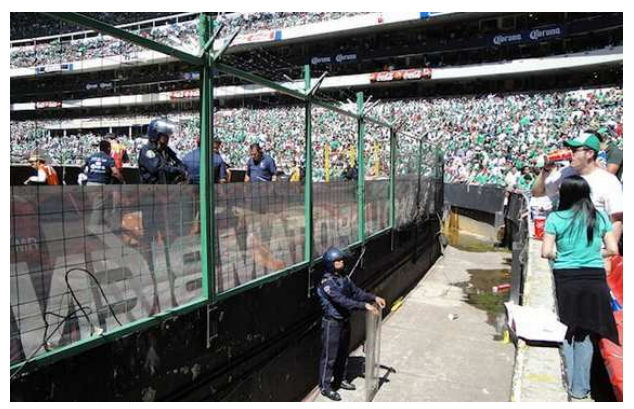

Slika 9. Ograda i betonski šanac između sportskog terena i gledališta. Izvor: How Donald Trump will Pay for the Wall. Preuzeto 15. maja, 2017. sa: https://bentcorner.com/donald-trump-wall/.

\section{Komfor gledalaca sa aspekta sagledivosti sportske priredbe povećanog rizika}

Opšte je poznato da na komfor sagledivosti aktivnosti u prostoru utiču dve grupe parametara, i to parametri objektivne i subjektivne prirode. Parametari objektivne prirode su kvantitativne vrednosti arhitektonskih svojstva prostora, odnosno fizičke determinante sportskog objekta, a to su: zapremina, površina, oblik osnove, geometrija preseka i druga arhitektonska određenja (visina, širina, dužina, raspored, materijalizacija i sl.). Druga grupa parametara, odnosno parametri subjektivne prirode, jesu personalni parametri i odnose se na indivuidualne karakteristike gledaoca $\mathrm{i}$ subjektivni osećaj sagledivosti aktivnosti u prostoru od strane gledaoca. Parametri subjektivne prirode izražavaju se godinama starosti, zdravstevnim stanjem (posebno zdravstvenim stanjem organa vida), metaboličkim aktivnostima i drugim ličnim karakteristikama gledaoca koji se nalazi u sportskom objektu. Uticaji parametara objektivne i subjektivne prirode nisu u fokusu ovog istraživanja.

U ovom radu istražuje se komfor gledalaca sa aspekta vidljivosti i sagledivosti sportskog terena, odnosno sportskog događaja, analizom uticaja arhitektonsko-fizičkih elemenata koji se postavljaju (montiraju) ili su izgrađeni na sportskom objektu (prvenstveno stadionu) u cilju, odnosno kao mere sprečavanja nasilja i nedoličnog ponašanja na sportskim priredbama pojačanog rizika. Cilj ovog istraživanja je da ukaže na problem sagledivosti sportskog događaja sa tribina, odnosno utvrđivanje uticaja arhitektonskih elemenata sportskog objekta koji predstavljaju mera za sprečavanje nasilja na sagledivost aktivnosti na sportskom terenu sa pozicije gledaoca koji se nalazi na tribini sportskog objekta/stadiona.

$\mathrm{Na}$ osnovu analize uticaja arhitektonskih mere odvajanja sportskog terena stadiona od gledalaca na komfor samih gledalaca sa aspekta sagledivosti sportskog terena, odnosno sportske aktivnosti na sportskim priredbama povišenog rizika, ukazujemo na sledeće: 
- podizanjem početnog nivoa gledališta od nivoa sportskog terena ili izgradnjom rova (šanca) između gledališta i sportskog terena povećava se udaljenost sportskog terena od oka posmatrača/gledaoca na tribinama, ali se na taj način umanjuje sagledivost sportskog terena, a time i vidljivost sportske aktivnosti na njemu za vreme sportske priredbama povećanog rizika,

- postavljanjem transparentne ograde između gledališta i sportskog terena umanjuje se vidljivost sportskog terena i sportske aktivnosti na njemu na sportskim priredbama povećanog rizika.

\section{Zaključak}

Dosadašnja primena znanja o komforu u polju projektovanja, građenja i opremanja sportskih objekata (posebno stadiona) zavisna su od tehnoloških, normativnih, higijenskih i kvantitativnih određenja, a najčešće polaze od osnovne teorije komfora. Ovim istraživanjem ukazuje se na to da je obezbeđenje komfora gledalaca u sportskom objektu mnogo kompleksnije od konvencionalne primene normirativa i standarda u ovoj oblasti. Takođe, istraživanjem je apostrofiran značaj kvalitativnih odnosa između arhitektonskih elemenata prostora sportskog objekta i doživljenog sportskog događaja od strane gledalaca u savremenim uslovima.

U radu je posebno ukazano na značaj propisanih standarda i normative koji se primenjuju pri arhitektonskom projektovanju gledališta sportskog objekta namenjenih sportskim takmičenjima, posebno stadiona, u cilju ispunjenja uslova komfora, u pogledu vidljivosti sportskog terena i sagledivosti sportskog događaja. U cilju prevencije nasilja i nedoličnog ponašanja doneta je regulativa kojom su propisane odgovarajuće mere kakve treba da ispuni sportski objekat namenjen održavanju sportskih takmičenja povećanog rizika. Od mera koje preduzima organizator sportskih priredbi pojačanog rizika na sportskom objektu (posebno na stadionima), u cilju sprečavanja nasilja ili nedoličnog ponašanja, odnosno (konkretno) ulaska gledalaca na teren - odvajanjem sportskog terena od gledališta - u radu su analizirana tri slučaja, i to: podignut nivo sedišta tribina, izgradnja šanca i podignuta transparentna ograda između gledališta i sportskog terena.

$\mathrm{Na}$ osnovu izvršenih analiza zaključujemo da sva tri analizirana slučaja odvajanja gledališta od terena negativno utiču na komfor gledaoca sa aspekta vidljivosti sportskog terena i sagledivosti sportske aktivnosti, odnosno praćenja sportskog događaja. Cilj istraživanja je ostvaren, jer je na argumentovan način ukazano na problem sagledivosti sportskog događaja sa tribina od strane gledaoca u kontekstu primene mera za sprečavanje nasilja i nedoličnog ponašanja na sportskim priredbama pojaćanog rizika. Istraživanje je prvenstveno od koristi arhitektama i građevinskim stručnjacima pri projektovanju, izgradnji i opremanju sportskih objekata (posebno stadiona), sportskim menadžerima u upravljanju sportskim objektima (sa prostorom za gledaoce) i organizatorima velikih sportskih priredbi pojačanog rizika, gde je neophodna preventivna primena mera sprečavanja nasilja i nedoličnog ponašanja. 


\section{Literatura}

1. Zakon o sportu, Beograd: Službeni glasnik Republike Srbije, br. 10/2016.

2. Zakon o sprečavanju nasilja i nedoličnog ponašanja na sportskim priredbama, Službeni glasnik Republike Srbije, br. 67/2003, 101/2005 - dr. zakon, 90/2007, 72/2009 - dr. zakon, i 111/2009.

3. Nacionalna strategija za borbu protiv nasilja i nedoličnog ponašanja na sportskim priredbama za period od 2013. do 2018. godine, Službeni glasnik Republike Srbije, br. $63 / 2013$.

4. Guide to Safety at Sports Grounds, London: Department for Culture, Media and Sport, 2008. Preuzeto 15. maja 2017. sa: http://www.safetyatsportsgrounds.org.uk/sites/default/files/publications/green-guide.pdf

5. Nojfert, E., Arhitektonsko projektovanje - Priručnik za građevinske stručnjake, predavače $i$ slušaoce, četvrto izdanje. Beograd: Građevinska knjiga, 1988.

(Naslov originala: Ernst Neufert, Aufentwurfslehre, 31. durchgesehene Auflage, Friedr. Vieweg \& Sohn Verlagsgesellschaft GmbH, Braunschweig, 1982.)

6. Neufert, E. Architects' Data. Preuzeto 16. maja 2017. sa: https://www.neufert.3th.pdf

7. Bošković, B., i Petrović, B., Menadžment sportskih objekata - skripta. Beograd: Fakultet za sport, Univerzitet „Union - Nikola Tesla“, 2014.

8. Football Stadiums / Technical Recommendations and Requirements, 2007. Preuzeto 15. maja 2017. sa: http://www.ksi.is/media/mannvirki/FIFA_Football_Stadiums.pdf

9. UEFA Guide to Quality Stadiums, Geneve: UEFA, 2011. Preuzeto 16. maja 2017. sa: https://www.uefa.org/MultimediaFiles/Download/EuroExperience/competitions/General/ 01/74/38/69/1743869_DOWNLOAD.pdf

10. FIFA Stadium Safety and Security Regulations, Zurich: FIFA, 2012. Preuzeto 14. maja 2017. sa: https://www.fifa.com/mm/document/tournament/competition/51/53/98/ safetyregulations_e.pdf

11. UEFA Stadium Infrastucture Regulations - Edition 2010, Geneve: UEFA, 2010. Preuzeto 16. maja, 2017. sa: https://www.uefa.com/MultimediaFiles/Download/Regulations/uefaorg/Stadium\&Security/01/48/48/85/1484885_DOWNLOAD.pdf

12. Zakon o sportu - podzakonska akta prema Zakonu o sportu, Beograd: Ministarstvo omladine i sporta Republike Srbije i Sportski savez Srbije, 2013.

13. Pravilnik o uslovima za obavljanje sportskih delatnosti, Beograd: Službeni glasnik Republike Srbije, br. 63/2013.

14. Kovačev, M., Minimalni standardi za održavanje sportskih takmičenja, Novi Sad: Pokrajinski sekretarijat za sport i omladinu, 2010.

15. Ilić, S., Sportski objekti, Beograd: Edicija Archigram, knjiga II, 1998.

16. Savković, M. i Đorđević, S., Na putu prevencije nasilja na sportskim priredbama: predlog regionalnog okvira saradnje, Beograd: Beogradski centar za bezbednosnu politiku, 2010. Preuzeto 14. maja 2017. sa: http://www.bezbednost.org/upload/document/na_putu_prevencije_nasilja_na_sportskim_priredbama.pdf

17. Kuzović, D., Management of Movement of Visitors in a Sports Facility. Physical Culture, vol. 71 (1): str. 63-68. Beograd, 2017 (UDC: 796.02:005, doi: 10.5937/fizkul1701063K). Preuzeto 14. maja 2017. sa: http://scindeks.ceon.rs/article.aspx?query=ISSID $\% 26$ and $\% 2613224 \&$ page $=6 \&$ sort $=8 \&$ stype $=0 \&$ backurl $=\% 2$ fissue. aspx $\% 3$ fissue $\% 3 \mathrm{~d}$ 13224 


\title{
PREVENTION OF VIOLENCE AT STADIUMS AND COMFORT OF THE VIEWERS - FROM THE ASPECT OF OBSERVATION OF THE SPORTING EVENT
}

\begin{abstract}
Summary
Violence and misbehaviour at major sporting events has become a global phenomenon and threatens the fundamental values of sport. Stadiums are the most important sports facilities because large international or national sports competitions are held there, with the highest number of viewers. Many studies indicate that violence is the most often at football matches. Place of the risk on the stadium is the auditorium. Because of the advent of violence and misbehaviour at the stadiums, it is necessary to provide security measures to prevent these negative social phenomena. This paper points to the measures and conditions to be met by sports facility in order to prevent violence and misbehaviour at major sporting events. Among the most important measures are: ensuring the safety zone, respectively ensuring minimum distance between the audience and the arena, separating the auditorium into sectors and separating the audience from the arena. During the design process of the stadium, auditorium is necessary to achieve the following main functions: good visibility for spectators, violence and misbehaviour prevention in the stands and also protection of the spectators, athletes and other stakeholders of sports competitions at the same time. The paper analyses the impact of the implementation of measures for prevention of violence and misbehaviour by spectators at the comfort of viewers in terms of the visibility of the event for the stadium.

The subject of the research is the regulations on the prevention of violence and misbehaviour at sporting events and regulations in the field of urban planning and architectural design of sports infrastructure, particularly stadiums. This paper studies the conditions for the design of the stadium audience, particularly in terms of the visibility of sport competition, or arena, distance between the audience and the arena and separating the audience from the arena. At the same time it studies regulations governing the sport, a special regulation regarding the prevention of violence and misbehaviour by spectators in the stands of the sports facility during sports competitions.

The aim is to determine the correlation between designing conditions for ensuring good visibility for the spectators from the stands of the stadium, and pragmatic measures to separate the arena, which are applied preventively to disable violence and misbehaviour during major sporting competitions.
\end{abstract}

Keywords: sports facility, violence prevention, observation 